\title{
Road Safety Literacy for Speakers of English as a Foreign Language: Educating novice drivers for the public's health safety
}

\author{
JINGHE HAN, MICHAEL SINGH, DACHENG ZHAO
}

\begin{abstract}
The public health dimensions of road safety literacy for novice drivers who speak English as a foreign language, are a concern due to increasing transnational mobility. The research literature indicates interest in this language issue in terms of comparisons with native English speakers, gender, and international evaluations. However, studies of road safety as a literacy issue are limited. Using an autobiographical approach this paper explores the textual, inter-textural and performative literacy of a Chinese learner-driver in Australia. Evidence of the learner-driver's life history, use of multiple languages, and cultural differences are shown to impact on her development of road safety literacy.
\end{abstract}

\section{Introduction}

Road traffic, public health and education authorities across many countries are concerned about finding ways to improve public health through better road safety (Escalera, Moreno, Salichs \& Armingo 1997, Korica \& Maurer 2005, Australian Transport Council 2006). Research into drivers' capabilities, characteristics and behaviours focuses on the relationship between users' responses to road signs and what this means for public health and safety (Al-Yousifi 2000, Al-Madani \& Al-Janahi 2002a, 2000b, British Department of Transport 2004). However, studies of the public health dimensions of what we call 'road safety literacy' in English speaking countries by learner-drivers who speak English as a foreign language (EFL)or as a second language (ESL) appear to be limited. This is so despite people's increasing trans-national mobility.

The practice of driving involves (a) learning to read certain forms of texts that are on the roadway (visual and audible), (b) understanding that a driver's licence is an official qualification from which authorised institutions (police, courts) can withdraw credit, as well as, (c) coming to embody certain practices whereby the learner comes to look like a driver with certain capabilities, having a new social standing and sense of freedom, as much as having the potential for death or debilitation. In this sense, we see road safety literacy as having a role to play in the public health of individual drivers, the community of road users and those in society who deal with the costs of road trauma. This idea of 'road safety literacy' resonates with work of the English Teachers' Association and the Roads and Traffic Authority (2007) of New 
South Wales (Australia), who have provided curriculum resources for exploring the issues of authority and drivers. Conceived in this way, the idea of 'road safety literacy' offers a conceptual tool for situating the practice of educating learner-drivers in relevant social contexts.

Road safety literacy is usually developed in the country where we are born, and thus, undertaken in our native language. Trans-national mobility sees increasing numbers of people from countries where English is a foreign language moving to countries such as Australia where as learner-drivers they meet road conditions that may differ from those in their home country. Given the public health issues at stake, there is a need to investigate the road safety literacy of EFL and ESL learner-drivers in this context.

This paper contributes to the study of road safety as a site of adult literacy development. It reports the results of an exploratory study of the scaffolding of road safety literacy for an EFL learner-driver in Australia. But first we introduce the theoretical framework to explain further the concept of road safety literacy used in the research reported here. This provides the basis for the ensuing review of the literature, which provides insights into relevant road safety research. This is followed by a brief account of the research method used in this study, and the key findings.

\section{A three dimensional view of road safety literacy}

The research reported here is broadly situated in the approach of New Literacy Studies which has shown that literacy is not a single, unified set of skills or competences, but rather that there are many different literacies associated with a range of different social practices (Street 1998). What then of the everyday literacy practices involved in learning to drive a motor vehicle, a fairly ubiquitous practice in Australia, and increasingly in China? Driving is an expression of popular culture, a means of communication, and the negotiation of a technology requiring particular reading skills. The safe use of motor vehicles can enhance civic, economic, and personal participation. It has to respond to changes in automobile technologies and requires multifaceted interventions, which benefit from being considered from multiple perspectives. Road signs, digital or otherwise, are part of the everyday texts that impose literacy demands on the diversity of road users. This includes those who speak English as their only language as well as those for whom it is one of two or more languages in their communicative repertoire.

In examining the EFL driver's learning of road safety literacy, the multiliteracies pedgagogical framework developed by Cope and Kalantizis (2000) was useful. Firstly, the learning was studied as an example of situated practice (Cope and Kalantzis 2000) by working with the learner's real-life experiences of learning to drive. To add to the situation at hand, the learnerdriver used her prior knowledge from home, school, communities and 
culture to contribute to her learning. Secondly, overt instruction (Cope and Kalantzis 2000) was involved through the instructor giving direct instructions during the lessons. Thirdly, Cope and Kalantzis' (2000) idea of critical framing was used in examining how the learner discerned the context and purpose of driving, which in turn added to the learner's perception of her identity as a driver and social context. Fourth, Cope and Kalantzis' (2000) notion of transformed practice could describe how the learner-driver brought her 'embodied understandings' into this context and site of popular culture (Pahl \& Roswell 2005: 91).

To understand road safety as a form of literacy, Blau's (2003) three dimensional (3-D) view of literacy was chosen. For Blau, textual literacy firstly refers to the 'procedural knowledge that allows a reader to move from summarising or retelling the plot of a story, to constructing a plausible interpretation, to reflecting critically on a text' (Blau 2003:19). For example, a learner-driver can demonstrate this textual or operational dimension of literacy by decoding and pronouncing words such as 'no right turn'.

Second, inter-textual literacy refers to the 'conceptual and informational knowledge that readers need to make sense of what they read, beyond what they would understand merely by pronouncing and decoding the words of a text' (Blau 2003:19). Presented with multiple road texts, such as traffic signs and road markings, drivers have to activate their inter-textual literacy. By way of illustration, a learner-driver has to become competent in make meaning of these texts in relation to their context, by using prior knowledge of this information to explain correctly what the various forms of road signs designating 'stop' mean in legal terms, and to distinguish these from, and relate them to, other signs, such as the brake light of a vehicle.

Third, performative literacy has been identified as 'knowledge that enables readers to activate and use all the other forms of knowledge that are required for the exercise of anything like a critical or disciplined literacy' (Blau 2003:19). Thus, a learner-driver who is unable to integrate the meaning of road signs, the safety consequences, and the legal implications of ignoring the sign would demonstrate limited performative literacy, and in turn pose a public health and safety risk.

By its nature this 3-D view recognises the existence of interrelated forms of literacy, which have implications for the producers and consumers of everyday texts, including EFL/ ESL adults learning to drive safely. This view allows us to supplement considerations of book-based literacy with the multiple message systems with which drivers must continuously engage to ensure public health and safety on the roads. The changes in the demographic features of Australian society, especially its increasing linguistic diversity, suggest drivers' engagement with these everyday texts may benefit from being understood in terms of how the learner-drivers construct, communicate and deconstruct them. Having introduced the theoretical 
framework to explain the concept of road safety literacy, we now review of the literature on road safety research.

\section{Road safety literacy and public health}

Road crashes are a major public health issue: 'road trauma is a major contributor to diminished public health. It is the leading cause of death among young Australians' (Australian Transport Council 2006:24). For each road death there are approximately thirteen serious injuries involving the loss of quality of life and requiring costly rehabilitation. The pain, grief and suffering of road trauma victims impose massive burdens on families, friends and the community.

Relative to native English speakers (NES), EFL drivers do not have an increased frequency in the display of dangerous driving behaviours. An Australian study found that the difference in road safety literacy between EFL and NES road users was inconclusive (Haworth, Symmons \& Kowaldo 2000). Predictors of an accident or involvement in illegal driving behaviours went beyond English language proficiency.

EFL women are, however, at a greater risk in terms of performative literacy relative to their NES peers. Dobson, Brown, Ball, Powers and McFadden (1999) examined factors which affected the driving behaviour and accident rates among EFL and NES women in Australia. Like the study reported in this paper, self-reported data were used. The study by Dobson et al (1999) suggested the need to further investigate factors that might account for the higher rate of public health risk among EFL women drivers. This could enable the development of driver education programs from which they and others could benefit.

Traffic accidents are a serious problem in the Asia Pacific region from where Xiaohua, the participant in this study, came. According to China Road Traffic Accident Statistics, in 2005 there were 450,254 traffic accidents in that country, with 98,738 people killed. The death rate per ten thousand registered motor vehicles was 10.82 persons (Zhang, Huang, Roetting, Wang $\&$ Wei 2006). The number of fatalities is expected to grow due to the increasing number of motor vehicles in China. In contrast, the number of people killed by traffic accidents in Australia in 2005 was 1,636 (Australian Bureau of Statistics, 2007). The Australian fatality rate from road traffic accidents per ten thousand registered motor vehicles was 1.2 persons. Zhang et al (2006) found that in contrast to drivers from Western countries, Chinese drivers did not concentrate on pedestrian safety. One possible explanation could be that institutions in China, which elsewhere had responsibility for road safety literacy, do not strongly support this field of public education.

There are national and cultural differences between Australia and China in road safety literacy. It is a very serious public health problem in China (Hu, Zhou, Zhao \& Liu 2005). The limited driver education has not 
been successful, with people's literacy with respect to road safety being low. According to Hu et al (2005), the high rate of traffic accidents in China is partly due to the low levels of textual, inter-textual and performative literacy among both pedestrians and drivers. Apparently, neither grouping of road users is adequately educated in the public health issues of road safety, with many not demonstrating performative literacy at traffic signs. For example, people randomly cross streets in Chinese cities rather than doing so at pedestrian crossings. Likewise, cars dash through red lights, while drivers ignore speed limits or enter prohibited traffic zones.

Driving is a skill-based, rule-governed, expressive activity. Parker and Stradling (2001) found that novice drivers are likely to be involved in a crash in the first year after getting their licences. They argue that there are three phases in learning to drive. First, in the technical mastery stage the neophyte driver learns how to operate a motor vehicle. Second, the stage of reading the road occurs when the driver learns to comprehend road signs, anticipate the actions of other road users and assess road surfaces and weather conditions. Third, the expressive stage sees the driver develop his/her own driving style based on personal, attitudinal and motivational characteristics. Parker and Stradling (2001) found that novice drivers have poor performative literacy when handling ill-defined and unusual road conditions relative to experienced drivers

There is much research-based knowledge relating to road safety issues across a wide variety of disciplines including transport, psychology, health and anthropology. This paper adds to this literature by looking at road safety as a literacy issue. The New South Wales English Teachers' Association (ETA) and the Roads and Traffic Authority (RTA) (2007) are engaging young adults in exploring what driving means in terms of the ideas and practices of selfregulation in the community and civil society. This partnership between road traffic authorities and English language educators offers a means for achieving cross-professional linkages and effective collaboration in improving road safety literacy. It addresses the need, identified by the Australian Transport Council (2006: 42-43) for sound driver education programs to improve higher-order cognitive skills, self-monitoring of driving behaviour, and appreciation of the consequences of performative actions.

The study reported in this paper provides an initial exploration of the possibility of considering 'road safety literacy' as a way of developing selfreflective learning about road safety among speakers of English as a foreign or second language working in Australia. The next section explains the approach to studying road safety literacy used in this project reported here.

\section{Method}

Changes in the demographic features of post-White Australia have increased the need to investigate how learner-drivers who speak English as an 
additional language construct, communicate and deconstruct the everyday texts of the road. The aims of the study reported here are to open up to further investigation the idea of road safety literacy by providing a preliminary exploration of strategies for developing it among EFL and ESL learnerdrivers.

Using an autobiographical approach thirty-seven-year old Xiaohua (pronounced Sh-ow-wha) documented her experience of learning to drive in Australia, just three and half years after arriving in this country. Xiaohua, a speaker of English as foreign language, had no previous driving experience in either China or Australia. Wright (2003) argues that the legitimacy of autobiographical approaches in empirically grounded investigations has come with the increasing use of auto-ethnography and reflexivity in educational research. Among the reasons for using an autobiographical approach to research literacy as a social practice, two are worth noting here: making the personal public, and opening up the possibility of moving from self-study to larger-scale research (Bullough \& Pinnegar, 2001).

First, because one's troubles cannot be solved when framed merely as personal matters, autobiography provides a means of positioning them as public issues. Thus, this project provided an opportunity for Xiaohua (a pseudonym) to reflect on, and to turn her personal experiences of learning to drive into a public account that could speak to others. However, the description provided here is not meant to be read as representative of the experience of learning to drive of other Chinese people in Australia, let alone other EFL speakers from Asia.

Second, autobiography is a long established form of self-study that provides an entrée into developing large-scale empirical research, which can speak to the needs of both the producers and the consumers of research. The autobiographical evidence upon which this paper is based provides a basis for clarifying the concept of road safety literacy. This study of how one individual learnt to drive, uses an analytical procedure that gives preference to the literacy dimensions of road safety. In this way, this autobiographical selfstudy provides a means for opening up the prospects for more elaborate research. However, the use of autobiography does not mean that the argument made here has a weight that places it above and beyond criticism. No claim is made for the unquestionable authority or authenticity of autobiographical research.

Further, our methodological thinking has been informed by Carr's (1964) argument that the knowledge produced by an individual represents an accumulation of knowledge from different people and across different countries. Xiaohua's driving was not enacted in isolation: she is a social being who acted in context and under the rules and practices of Australian society, while bearing the influence of related experiences in China. Thus, it is important to appreciate the standpoint from which she herself approached 
her driving, and to see that standpoint as having a social grounding and as being rooted in her life history.

The method for data collection involved Xiaohua writing down her experiences after each driving lesson. These recounts included her feelings about the differences between being a pedestrian and driver; being a foreigner learning to drive in Australia; and being literate in both the Chinese and English languages while being relatively illiterate in matters relating to road safety in both Australia and China. As noted above, in this study, this evidence of her road safety literacy was then analysed using a three dimensional theory of literacy (Lankshear, Snyder \& Green 2000, Blau 2003), namely textual, inter-textual and performative literacies. After the open coding of the data, the analysis was used to frame the interpretation of the evidence generated for this study in terms of these three dimensions of literacy (Emerson, Fretz \& Shaw 1995).

\section{Findings}

This section presents an analysis of evidence of Xiaohua's reflections on her developing road safety literacy as she learned to drive. In doing so, she understood herself as becoming a productive member of society, learning English and learning about Australian/Chinese driving cultures. Her learning experiences were not unlike those represented in the curriculum materials produced by the ETA \& RTA (2007). The research found that Xiaohua started with very limited textual capabilities for road safety literacy, which, to a large degree, were influenced by her personal experience or life history. Her inter-textual level of road safety literacy was influenced by her bilingual processing of information, a function of her rich communicative repertoire. Xiaohua's performative level of road safety literacy was shaped by the culture of road use in both Australia and China.

\section{The impact of a learner-driver's life history on textual road safety literacy}

Road texts only entered Xiaohua's consciousness when she started her driving lessons, 'There weren't many road signs in my life before I learned to drive. I looked but did not see them. I was not a driver so did not care about the signs'. Xiaohua did not have the 'textual literacy' (Blau 2003) to decode the formal or informal road texts. She had no self-generated or externally imposed purposes for doing so.

Barton (1994) points to the importance of considering the influences of personal goals in literacy learning and practices when these are being researched. For learner-drivers who are from another country it is worth considering their different transport and driver education systems. Xiaohua's experiences had marked her: 
Back to 1970's when I was very young, there were not many motor vehicles on roads in China. There was no formal road safety education in my schooling. It was not necessary. Primary school children are now given basic road safety knowledge. They are taught how to react to traffic lights, and how to use pedestrian crossings. Road safety knowledge is still largely absent.

Xiaohua was not taught road safety literacy during her schooling in China. Despite the increase in traffic since the 1980s, children's education about road safety is still limited (Yu, Zhang, Wang \& Yan 2003). While Chinese school children can fluently recite traffic rules, a form of textual literacy, they are puzzled when it comes to the inter-textual and performative literacies these rules require.

The concepts of driving and becoming a driver mean different things in different contexts. Xiaohua had to deal with international differences in licensing procedures:

When I lived there, there was no minimum of 120 hours of required practice in my city, a provincial capital in Northern China. Learner-drivers do not need to sit a test of road rules. There is only a driving test. Reverse parking is the most important task in the test. If you can do that properly, you will probably get your licence. Many people receive their driving licence before they can drive.

When a young adult learns to drive, s/he not only moves across subject areas, but across semiotic systems, value systems and embedded meanings and their assumptions (Pahl \& Roswell 2005). For Xiaohua, who had been living in Australia for three and half years before learning to drive, most of the road texts were new to her. This is because she had never had any driving practice in either China or Australia. The research literature indicates that personal life history is important to literacy, particularly in understanding the self-regulation required to link social choices and individual behaviour (Barton 1994).

For Xiaohua, an EFL learner-driver, getting a driver's licence in Australia involved acquiring knowledge of road rules and driving practice in order to demonstrate this knowledge in action before taking the road test. In contrast, following Parker and Stradling (2001), it seems that novice drivers in northern China focus on limited technical aspects of learning to operate a motor vehicle. Apparently, there is not enough training at the textual level of road safety literacy. In addition, the learner needs to understand the wide range of discourse strategies which go beyond the grammar and pragmatics of road use. Interaction within wider social contexts needs to be analysed in order to focus on the needs of the learner-driver (Pahl \& Roswell 2005). 


\section{A foreign language speaker and inter-textual road safety literacy}

Besides concentrating on her driving skills, Xiaohua needed a longer time to deal with the inter-textual issues of working in two languages:

When I started, I couldn't read the road signs because I needed to keep my eyes on the road and to make sure my car was centred in the lane. My driving instructor acted as the guide for my driving. My reaction time took the following sequence: the instructor read the signs - the instructor then spoke to me in English - I worked out the meaning in Chinese - I then reacted. I felt 40 kilometres per hour was already too fast. I put my foot on the brake most of the time. I prepared to stop anytime when I was not sure.

Being an EFL learner-driver, Xiaohua was slow to react to the array of road signs and her reading of the traffic flow and the movement of individual vehicles. After the input of these multiple road texts, her mind's processing of this inter-textual information meant that her reaction time was longer than might be expected of NES learner-drivers. That is, the language translation step she had to engage in, itself an inter-textual move, necessarily affected her performative literacy on the road. The time this took added to her sense of frustration and thus her risk to public safety on the road. The processes of becoming of a different type of person, a novice driver, presented problems at the level of inter-textual literacy for Xiaohua:

I was having difficulty changing my identity from a pedestrian to a driver. I seriously doubted whether I had the right to be on driving road. As a pedestrian my road use was always challenged by drivers. At the beginning I tried to avoid other motor vehicles. I was ready to stop for any other cars that would join me on the road. As soon as I saw a car was coming, I slowed down and prepared to stop.

As a pedestrian Xiaohua was used to seeing vehicles on the road but had no sense of how to read the road as a multi-dimensional text. As a pedestrian she lived in a different language field. For a period of time her eyes were blind and her ears were deaf to the inter-textual literacy she had to engage on the road. She worried about the other vehicles but could not see or work out the meaning of the various, often competing road texts whether it be the road signs, the traffic flows or the road surfaces.

Learner-drivers experience stress due to uncertainty about the safety of their driving because they are new to this experience. Xiaohua confronted the inter-textual challenges of learning to drive: 
I worried the road might disappear around the next corner or over a crest. So whenever in this situation I pressed the brake very hard. I did not know how to read the road signs. When I couldn't see anything beyond the crest, I started to worry and react anxiously.

Inter-textual literacy refers to the ability to relate multiple texts to each other - 'both those which texts implicitly take for granted or explicitly allude to, and those which readers bring to their reading of them' (Macken-Horarik 1998:76). The inter-texts are all the other texts that we do or can use to make sense of a given text. These will vary from reader to reader, and from community to community. That is to say, learners bring into their learning not just experiences of 'reality' but experiences of different kinds of texts. The understanding a learner makes of a text to some extent depends on what other texts $\mathrm{s} /$ he views as relevant to its interpretation.

Inter-textuality involves two perspectives: the learner and his/her experiences, and the text and all the other texts it implicates. Texts constrain the possible interpretations that can believably be made of them but learners take these up in different ways. Inter-textuality depends on both the learner's interpretive framework and the writer's productive capabilities (MackenHorarik 1998) and these two aspects both need to be brought into considerations of road safety literacy. At one stage Xiaohua was not able to read the warning signs and the changes in the road itself to make judgements about what she might anticipate or plan to take appropriate actions. She had to learn to read the road signs and link these to the condition of the road ahead, irrespective of whether it could be seen or not. Xiaohua had to learn to read these texts together, and know that this required her to prepare for possible changes, while not worrying unduly about the part of the road she could not see. Her inter-textual reading of road texts was made all the more difficult because initially she could neither see nor read the inter-textual relations presented.

\section{Learners' literacy identity and performative road safety literacy}

Literacy is a social practice, involving specific literacy knowledge as well as social and cultural behaviours. Learners' literacy identity includes 'social and cultural resources, technological experience, and all previous life experiences, as well as specific literacy knowledge and experience' (Anstey \& Bull 2006:35). Learners' life experiences are essential resources for literacy practices. These resources contribute to each learner's identity and inform their meaning making (Barton, Hamilton \& Ivanic 2000).

Xiaohua's performative literacy was affected by her Chinese identity and its socio-cultural resources. For example, once while driving across a 
zebra crossing, she did not have any intention to slow down even though some pedestrians were crossing the road at that point. After this she reflected that:

In Australia "zebra crossings" give pedestrians safety to cross the road. Drivers have to be cautious when pedestrians are using these. However, in the city where I used to live in China, I observed that drivers never stop for the pedestrians and pedestrians can only pass when there are no cars approaching. Even then you have to run across it quickly.

Xiaohua's example indicates how laws governing the relationship between drivers and pedestrians can be ambiguous. The traffic law in Australia gives priority to pedestrians in this particular context, while in China zebra crossings do not guarantee their safety. Literacy is embedded in larger social conditions governing what is possible (Barton 1994: 43), and this applies specifically to road safety literacy. If instructors can help learners to reflect on their literacy identities and resources, they become more flexible and strategic in their literate activities (Anstey \& Bull 2006: 35).

Lacking technological experience in her previous life distracted Xiaohua from the performative skills needed for road safety literacy. For this learner-driver, being able to integrate her operational skills into developing performative literacy was a challenge:

At first I couldn't control the vehicle well. Sometimes I drove into the next lane. I had to try hard to keep my eyes on the lanes. I had no sense of accurately judging distance. I felt as though my car was wider than the lane. I complained about the narrowness of the roads. Because I was concentrating on the road lanes, I had no third eye to look at the road signs so had to ask my instructor what to do next. I gave the task of my eyes to my ears.

Learning to make and act on her own decisions was a key step in Xiaohua's performative literacy:

I was used to getting guidance from my diving instructor. Once I was approaching the traffic light, I had no idea whether I should keep driving when there was no car in front to lead me, while some others on my right were waiting. Later I knew they were waiting for a 'green' arrow to turn right. When I approached the traffic lights, I only saw the colour of the light in front but didn't see the arrows on the road. When I did see them, I did not make meaning out of them. At this time, I had to ask my instructor what to do. Later I took the risk of making my own decision. 
For Xiaohua, there was a distance between knowing the textual meanings of the road signs and what or how to react to them. She had to learn to make the right decisions. She could read the green light, which meant to go. At the same time she needed to consider the other road texts such as arrows in each lane, differences in the types of white lines in front of her, and signs giving directions. While she was able to read and understand one single piece of road text, she could not read many road texts simultaneously and then perform appropriately with due regard to other road users.

An important indicator of her capability to connect inter-textual and performative literacy was that Xiaohua could understand and act on the legal dimensions of road texts:

At the beginning, I did not believe that the signs meant the law, and that drivers must follow them. I always worried that some drivers wouldn't obey the rules. So many times when the traffic light was green, I was still not sure whether I should go without my instructor's words because I thought some one might break the rules and bump into me while I was driving through the green light. Also when I saw a car come out of a side-road, I always slowed down even though I had the 'right of way.'

While the authority of other drivers looked assured, Xiaohua's own sense of authority seemed tenuous. Even as she started to understand road signs at a textual level, she still could not believe or trust herself. Her worries were partially derived from her experience in China where the road culture is different from that in Australia:

An Australian TV program about China showed pictures of a traffic accident in Beijing. It looked like something from a movie, but it was a news report. The traffic lights did not work for some reason. A police officer stood in the middle of a major intersection. However, no drivers followed his instruction. Cars flew into the intersection and crashed into each other.

Xiaohua could not believe that the road texts were expressions of laws governing public safety which drivers and pedestrians needed to follow. Her scepticism was derived from her cultural experience. In China she knew that some people did not follow traffic rules, and so she doubted whether road users would do the same in Australia. This affected her performance in reacting to road texts, reinforcing her insecurity in performing as a learnerdriver.

As an EFL learner-driver Xiaohua took time to perform in a road emergency. For example, when visual information such as the image of a 'camera' and procedural texts such as ' 80 ' appeared at the same time, she had to decode both simultaneously. This involved ascertaining the meanings of the two text types, establishing their interrelationship and preparing to 
perform accordingly. Xiaohua also had to decode the texts by translating them into her native language when she was not sure of how she should react. Her performance came after she had sorted out the language issues, an added element in her performative road safety literacy.

\section{Conclusion}

Working within the framework of literacy as a social practice, this paper has opened up the possibility for more extensive investigations into driver education as a form of literacy learning. Learning to drive is a domain of life that requires the development of multiliteracies (Cope and Kalantzis 2000) that involves learning a situated practice through real-life experiences and overt instruction and guidance by an instructor. Moreover, it requires what Cope and Kalantzis (2000) calls critical framing as experienced by the learner-driver in this study who learned to critique what she knew, learned or inferred from the culture, politics and social economy of driving in China and Australia, as well as transformation of practice that led this learner-driver to develop a meta-awareness of what it means to be a driver in Australia as distinct from its meaning in her home country.

Road safety literacy involves beginning-drivers learning to read a diversity of texts, bringing in other relevant texts and performing, based on their understanding of these many texts. This is a process that is governed by the social relations established among drivers as much as by the institutional powers involved in creating roads, governing traffic flows and policing driver behaviours.

Road safety literacy practices are purposeful and embedded in broader social goals and cultural practices. They are situated in terms of both the individual's life history and societal changes. Therefore, the pedagogy of road safety literacy involves learners using, and sometimes not using, their prior knowledge to contribute to their learning, comparing the meaning differences of road texts in different social contexts, according to different discourses (Gee 1996) and cultural capital (Cope and Kalantzis 2000). It can also involve learner-drivers in reflection and critique about what they know or have learned from their culture, politics and social economy. Instructing them so as to develop their meta-awareness of their embodied understandings is necessary to inform their meaning-making about the 'new' literacy they learn in becoming safe road users in Australia.

\section{References}

Al-Madani, H and Al-Janahi, A (2002a) Role of Drivers' Personal Characteristics in Understanding Traffic Sign Symbols, Accident Analysis and Prevention, vol 34, pp 185-196. 
Al-Madani, H and Al-Janahi, A (2002b) Assessment of Drivers'

Comprehension of Traffic Signs Based on their Traffic, Personal and

Social Characteristics, Transportation Research Part F, vol 5, pp 63-76.

Al-Yousifi, A (2000) Investigation on Traffic Signs to Improve Road Safety, in Proceedings of Conference on Traffic Safety on Two Continents Malmo, Swedish National Road and Transport Research Institute, Linkoping, Sweden, pp 71-87.

Anstey, M and Bull, G (2006) Defining Multiliteracies, in Anstey, M and Bull, G, Teaching and Learning Multiliteracies, International Reading Association, Newark, Delaware, pp 19-55.

Australian Bureau of Statistics (2007) Year Book Australia, Australian Government Publishing Service, Canberra.

Australian Transport Council (2006) National Road Safety Action Plan 2007 and 2008, Australian Government Publishing Service, Canberra.

Barton, D (1994) Literacy, Blackwell, Oxford, UK.

Barton, D, Hamilton, M and Ivanic, R (eds) (2000) Situated Literacies. Routledge, London.

Blau, S (2003) Performative Literacy, Voices from the Middle, vol 10, no 3, pp 18-22.

British Department for Transport (2004) Increasing Understanding of Traffic Sign, retrieved March 14, 2007 from

www.dft.gov.uk/pgr/roads/tss/research/increasingunderstandingof $\underline{\operatorname{tra} 4173}$

Bullough, R and Pinnegar, S (2001) Guidelines for Quality in Autobiographical Forms of Self-study research, Educational Researcher, vol 30, no 3, pp 13-21.

Carr, E (1964) What is History? Penguin, Middlesex.

Cope B and Kalantzis, M, eds (2000) Multiliteracies, MacMillan Publishers, South Yarra.

Dobson, A, Brown, W, Ball, J, Powers, J and McFadden, M (1999) Women Drivers' Behaviour, Socio-demographic Characteristics and Accidents, Accident Analysis and Prevention, vol 31, pp 525-535.

Emerson, R, Fretz, R and Shaw, L (1995) Writing Ethnographic Fieldnotes, The University of Chicago Press, Chicago.

English Teachers Association of NSW \& NSW Roads and Traffic Authority (2007) In the Driver's Seat, NSW Roads and Traffic Authority, Sydney.

Escalera, A, Moreno, L, Salichs, M and Armingol, J (1997) Road Traffic Sign Detection and Classification, IEEE Transaction on Industrial Electronic, vol 44, no 6, pp 848-859.

Gee, J P (1996) Social Linguistics and Literacies: Ideologies in discourses, Second Edition, Taylor \& Francis, London. 
Haworth, N, Symmons, M and Kowaldo, N (2000) Road Safety Issues for People from Non-English Speaking Background, retrieved March 10, 2007 from www.monash.edu.au/muarc/muarc176.pdf.

Hu, Q, Zhou, Z, Zhao, Y and Liu, Q (2005). Study on the Urban Road Traffic Safety Management, Proceedings of the Eastern Asia Society for Transportation Studies, vol 5, pp 2062-2074.

Korica, P and Maurer, H (2005) DynEST - Dynamically Explained Symbols for Traffic or Learning How to Drive Without Words, in Richards, G ed, Proceedings of World Conference on E-Learning in Corporate, Government, Healthcare, and Higher Education, Association for the Advance of Computing in Education, Chesapeake, VA, pp 829-835.

Lankshear, C, Snyder, I and Green, B (2000) Teachers and Technoliteracy, Allen \& Unwin, St Leonards, NSW.

Macken-Horarik, M (1998) Exploring the Requirements of Critical School Literacy, in Christie, F and Misson, R, eds, Literacy and Schooling. Routledge, London, pp 74-103.

Pahl, K and Roswell, J (2005) Multimodal Literacies, in Phal, K and Roswell, J, eds, Literacy and Education. Paul Chapman, London, pp 25-47.

Parker, D and Stradling, S (2001) Road Safety Research Report no. 17: Influencing Driver Attitudes and Behaviour, Department of the Environment, Transport and the Regions, London.

Street, B (1998) New Literacies in Theory and Practice, Linguistics and Education, vol 10, no 1, pp 1-24.

Wright, H (2003) Cultural Studies as Praxis, Cultural Studies, vol 17, no 6, pp 805-822.

Yu, Q, Zhang, Q, Wang, M and Yan, J (2003) Zebra Crossings. Asia Pacific Perspectives, vol 3, no 1, pp 50-55.

Zhang, W, Huang, Y, Roetting, M, Wang, Y and Wei, H (2006) Driver's Views and Behaviours About Safety in China, Accident Analysis \& Prevention, vol 38, pp 22-27. 